\title{
BMJ Open High-heeled shoes and musculoskeletal injuries: a narrative systematic review
}

\author{
Maxwell S Barnish, ${ }^{1}$ Jean Barnish ${ }^{2}$
}

To cite: Barnish MS,

Barnish J. High-heeled shoes and musculoskeletal injuries: a narrative systematic review. BMJ Open 2016;6:e010053. doi:10.1136/bmjopen-2015010053

- Prepublication history and additional material is available. To view please visit the journal (http://dx.doi.org/ 10.1136/bmjopen-2015010053).

MSB is the senior author and is currently at Epidemiology Group, Institute of Applied Health Sciences, University of Aberdeen, Aberdeen, UK.

Received 22 September 2015 Revised 10 December 2015 Accepted 14 December 2015

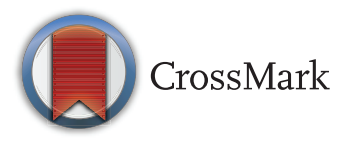

${ }^{1}$ Independent Scholar, Aberdeen, UK

${ }^{2}$ Retired Health Visitor, London, UK

Correspondence to Dr Maxwell S Barnish; maxwell.barnish@abdn.ac.uk

\section{ABSTRACT}

Objectives: To conduct the first systematic review from an epidemiological perspective regarding the association between high-heeled shoe wear and hallux valgus, musculoskeletal pain, osteoarthritis $(\mathrm{OA})$ and both first-party and second-party injury in human participants without prior musculoskeletal conditions.

Setting: A systematic review of international peerreviewed scientific literature across seven major languages.

Data sources: Searches were conducted on seven major bibliographic databases in July 2015 to initially identify all scholarly articles on high-heeled shoes. Supplementary manual searches were conducted. Titles, abstracts and full-text articles were sequentially screened to identify all articles assessing epidemiological evidence regarding the association between high-heeled shoe wear and hallux valgus, musculoskeletal pain, $\mathrm{OA}$ and both first-party and second-party injury in human participants without prior musculoskeletal conditions. Standardised data extraction and quality assessment (Threats to Validity tool) were conducted.

Primary and secondary outcome measures: Musculoskeletal pain or $\mathrm{OA}$ as assessed by clinical diagnosis or clinical assessment tool. First-party or second-party injury.

Results: 644 unique records were identified, 56 fulltext articles were screened and 18 studies included in the review. Four studies assessed the relationship with hallux valgus and three found a significant association. Two studies assessed the association with $\mathrm{OA}$ and neither found a significant association. Five studies assessed the association with musculoskeletal pain and three found a significant association. Eight studies assessed first-party injury and seven found evidence of a significant injury toll associated with high-heeled shoes. One study provided data on second-party injury and the injury toll was low.

Conclusions: High-heeled shoes were shown to be associated with hallux valgus, musculoskeletal pain and first-party injury. No conclusive evidence regarding $\mathrm{OA}$ and second-party injury was found. Societal and clinical relevance of these findings is discussed. Concern is expressed about the expectation to wear high-heeled shoes in some work and social situations and access by children.

\section{Strengths and limitations of this study}

- We present the first systematic review of highheeled shoes and health from an epidemiological perspective.

- We situate the evidence in the context of wider public debate.

- We were able to consider evidence published in seven languages.

- We could not include non-European languages and two articles were not retrievable.

- There was a lack of standardisation of heel height cut-offs between studies.

\section{INTRODUCTION}

High-heeled shoes (high heels) are a powerful symbol of modern female sexuality ${ }^{1}$ that have been shown to increase women's attractiveness to men and influence men's behaviour towards women in experimental studies. $^{2}{ }^{3}$ It has been suggested that this effect may result from an exaggeration of prototypical feminine gait. ${ }^{3}$ Compliance to social norms $4^{5}$ is a key driver of human behaviour and fashion ${ }^{6}$ including use of high heels ${ }^{78}$ is a clear manifestation of this. Being associated more with occasions than nonoccasions, ${ }^{78}$ use of high heels may be seen as highly desirable and even compulsory at certain workplaces and social events. ${ }^{9-12}$

Concerns regarding the potential impact of high heels on women's health have been expressed in medical circles for over 50 years $^{13}$ and in 2001 podiatrist William Rossi declared footwear to be the primary cause of foot disorders. ${ }^{14}$ A narrative review from an experimental biomechanical perspective in $2014^{15}$ concluded that high heels cause qualitatively consistent alterations to the neuromechanics of walking gait and affect the kinematics and kinetics of bodily structures from the toes to the spine in ways that may be seen as biomechanical markers of musculoskeletal conditions such as hallux valgus (HV) and osteoarthritis (OA), which are both more common in women than 
men. ${ }^{16}{ }^{17}$ However, no review from an epidemiological perspective could be identified and indeed a relative lack of epidemiological evidence was cited over 15 years ago $^{9}$ as a barrier to the introduction of measures to prevent women being required to wear high heels as part of employer dress codes.

Moreover, the potential for high heels to inflict injury both on the wearer and on bystanders should be considered. For example, Williams and Haines ${ }^{18}$ identified 240 emergency department (ED) presentations over a 5-year period in the Australian state of Victoria resulting from first-party injury from high heels and a further 65 resulting from second-party injury from high heels. Since pressure is inversely associated with the cross-sectional area through which a force is applied, ${ }^{19}$ the potential for high heel shoe wearing to result in injury to both the wearer and on bystanders should be considered. Such shoes are exempt from restrictions on wear in public places and age restrictions on sale that are imposed on other sharp bladed objects such as knives in countries such as the $\mathrm{UK}^{20}$ and Australia. ${ }^{21}$

The systematic review presented in this article sought to assess existing epidemiological evidence associating exposure to high heels with at least one of the following outcomes in human participants without clinically significant musculoskeletal conditions prior to measurement: (1) OA, musculoskeletal pain or HV verifiable either by clinical diagnosis or clinical assessment tool or (2) injury to first or second party.

\section{METHODS}

Design

A systematic review design was used following the PRISMA statement ${ }^{22}$ adapting the approach to the epidemiological rather than interventional nature of this review. MSB was the lead reviewer and JB performed independent quality assurance on a $20 \%$ sample of title screening, abstract screening, full-text screening, data extraction and quality assessment. Any discrepancies were resolved by discussion between the reviewers. Searches were designed and conducted by MSB.

\section{Data sources}

The bibliographical databases MEDLINE (Ovid), EMBASE (Ovid), AMED (Ovid), PsycINFO (Ovid), Cochrane Central Register of Controlled Trials (Cochrane), CINAHL (EBSCO) and Web of Science (Thomson Reuters, excluding patents) were searched from inception to July 2015. In order to maximise coverage, it was decided to search for all scholarly articles on high heels and then achieve greater focus through screening. Since there were no appropriate $\mathrm{MeSH}$ terms, databases were searched with the following keywords linked by the OR function: "positive heel inclination', 'high heel', 'high-heeled', 'high heeled', 'wedge heel', 'platform heel', 'platform shoe', 'stiletto' and 'elevator shoe'. This same exact combination of search keywords was presented to each database. Supplementary searches were conducted using Google Scholar, reference lists of relevant retrieved articles and also general internet searches using the Google search engine to identify media coverage and/or press releases on high heels and health in order to seek the original publication source.

\section{Inclusion criteria}

The following inclusion criteria were applied sequentially. Initially, titles and abstracts were screened and then full-text copies of all potentially relevant articles were sought. Full-text articles were retrieved in electronic form where this was available, otherwise in paper copy. An array of leading research libraries were accessible to the authors including the British Library. If an article could not be retrieved from any of these sources, it was excluded. A list of excluded articles with reasons is provided in online supplementary table S1.

- Full-text original empirical peer-reviewed scientific journal articles.

- Published in English, French, German, Spanish, Italian, Dutch or Portuguese.

- Able to be retrieved.

- Providing data to associate use of high heels with at least one of: (1) OA, musculoskeletal pain or HV verifiable either by clinical diagnosis or clinical assessment tool or (2) injury to first or second party.

- Assessing human participants without prior history of clinically significant musculoskeletal conditions or other serious medical conditions likely to affect outcomes.

- Using any quantitative epidemiological design including epidemiological elements embedded into biomechanical studies.

\section{Data extraction and quality assessment}

Data were extracted onto a standardised data extraction form. The following data were collected: bibliographic details, language of publication, country of study, study design, participants, measures of exposure, measures of outcome and principal findings. MSB contacted corresponding authors where appropriate to seek required clarifications. Measures of heel height that had been expressed in inches were converted to $\mathrm{cm}$ at 1 inch $=2.54 \mathrm{~cm} .{ }^{23}$ Only aspects of studies that meet inclusion criteria for this review are presented. Quality assessment was conducted at the study level using the Threats to Validity tool, ${ }^{24}$ which is a dynamic tool that is designed to be adaptable to any observational data set.

\section{RESULTS}

A concise summary of the included studies is provided in table 1. Detailed study characteristics are shown in online supplementary table S2, detailed results in online supplementary table S3 and detailed quality assessment in online supplementary table S4. Meta-analysis was 
Table 1 Summary of included studies

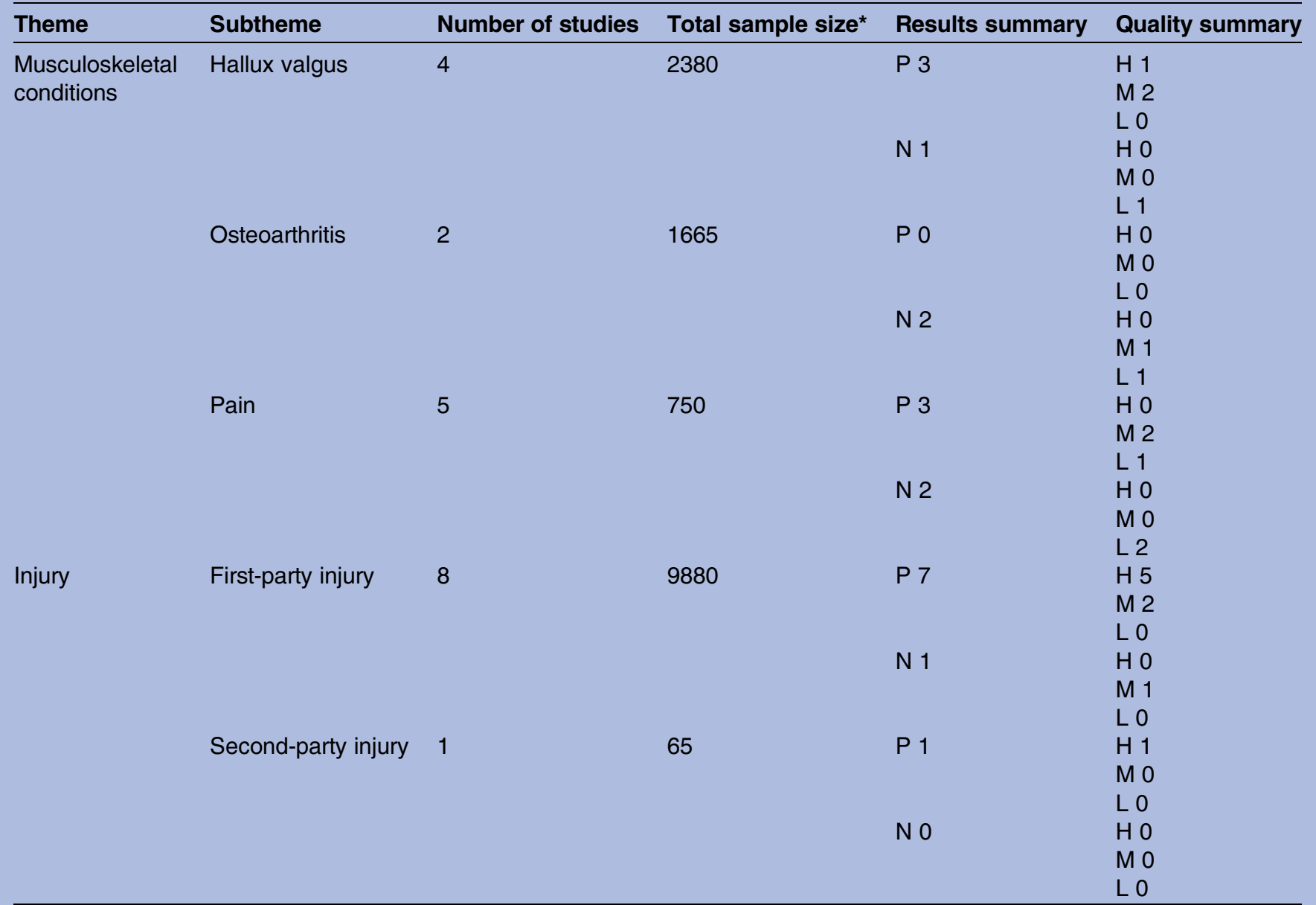

*Some studies measured the sample size in terms of number of incidents rather than number of participants.

$\mathrm{H}$, high quality (low risk of bias); L, low quality (high risk of bias); M, moderate quality (moderate risk of bias); N, negative result; $\mathrm{P}$, positive result.

unable to be undertaken due to the heterogeneity of results. Results were thematically described.

\section{Study profile}

Searches identified 644 unique records, of which 56 were screened at the full-text stage and 18 included in the review. Database searches yielded $95 \%$ of unique records and supplementary searches yielded 5\% (see figure 1 for detailed study flow chart). The total sample size was 14647 . Eleven studies $(61 \%)$ assessed heel height only in women, while seven studies (39\%) assessed both men and women. All studies fulfilling the inclusion criteria were published in English. Five studies were conducted in the USA, four in the UK, three in Australia, two in Taiwan and one in each of Brazil, Japan, Malaysia and Thailand. Six studies (33\%) were assessed as high quality, eight $(44 \%)$ as moderate quality and four $(22 \%)$ as low quality.

\section{Musculoskeletal conditions}

Four studies assessed the association between high heels and $\mathrm{HV}$ risk, of which three $\mathrm{e}^{25-27}(75 \%)$ found a significant association and one ${ }^{28}$ did not. Of the three positive studies, one ${ }^{25}$ was assessed as high quality and two ${ }^{26} 27$ as moderate quality. The negative study had a sample size of only 93 and was assessed as low quality. Menz and Morris ${ }^{26}$ found a significant association only with current not past use of high heels. Dufour $e t a l^{25}$ and Menz and Morris $^{26}$ both reported ORs. The former reported an OR of 1.24 for HV for those who 'sometimes' wore high heels in the past compared to those who 'never' wore high heels and an OR of 1.47 for those who 'always' wore high heels, while the latter reported an OR of 2.48 for $\mathrm{HV}$ for those who currently wore high heels outdoors compared to those who did not.

Two studies ${ }^{29} 30$ assessed the association between high heels and OA risk and neither found a significant association. One ${ }^{29}$ was assessed as moderate quality and the other $^{30}$ as low quality. Five studies assessed the association between high heels and musculoskeletal pain risk, of which three ${ }^{31-33}(60 \%)$ found a significant association and two $2834(40 \%)$ did not. Of the three positive studies, two $^{32} 33$ were assessed as moderate quality and one ${ }^{31}$ as low quality. Both negative studies were assessed as low quality. Chua et $a l^{31}$ provided an OR of 1.60 for the association between use of high heels and foot pain. Hong 


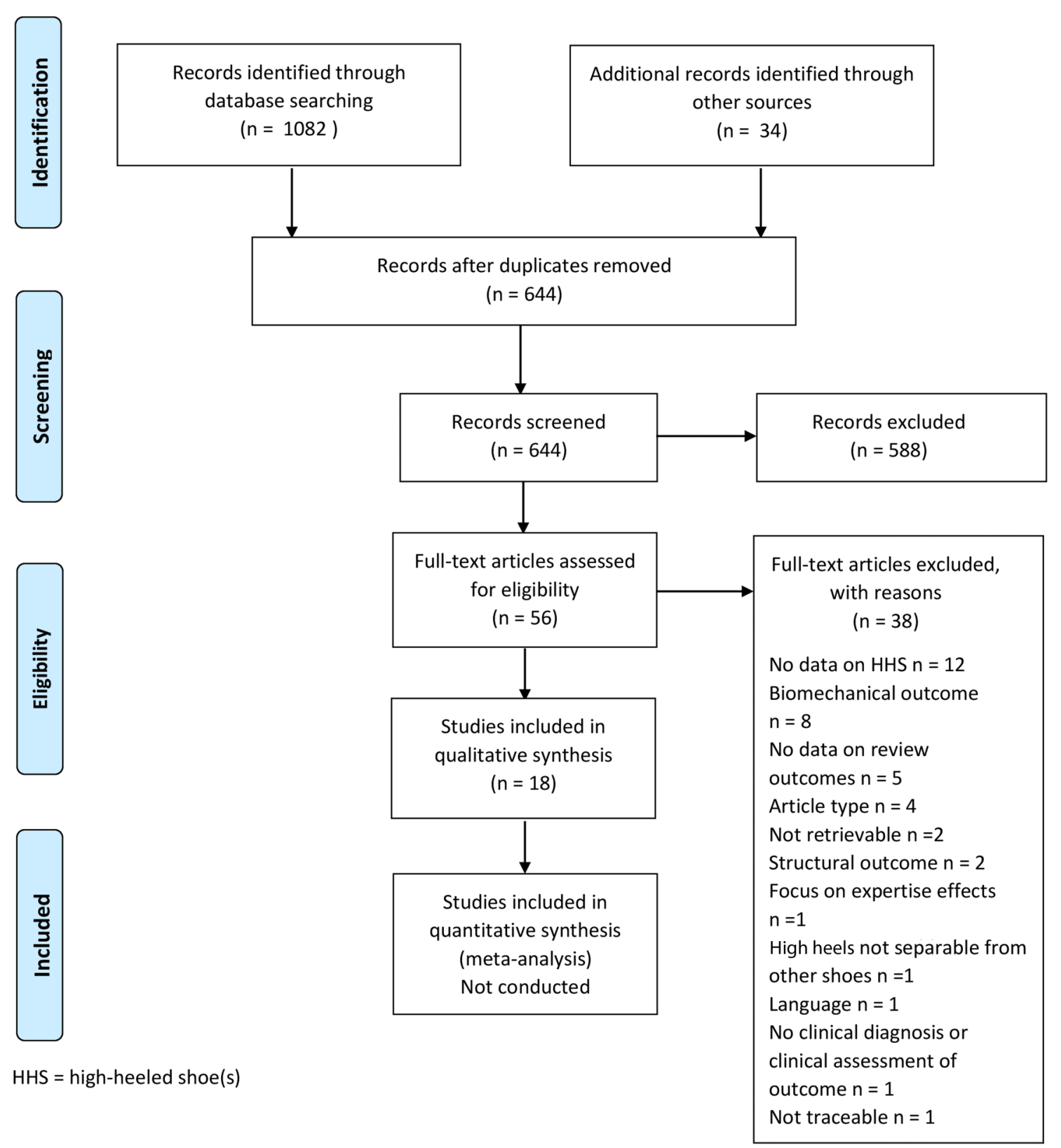

Figure 1 PRISMA flow diagram.

et $a l^{32}$ and Yung-Hui and Wei-Hsien ${ }^{33}$ provided analysis of variance $F$ values of 56.8 and 46.8 , respectively.

\section{Injury}

Eight studies assessed the association between high heels and first-party injury, of which seven ${ }^{18}{ }^{35-40}(88 \%)$ were positive and one ${ }^{41}(12 \%)$ was negative. Of the positive studies, five ${ }^{18} 35373840$ were assessed as high quality and two $^{3639}$ as moderate quality. The only negative study was assessed as moderate quality. Studies on first-party injury differed more in terms of design than other studies included in this review so require more detailed in-text results.

Chaiklieng and Suggaravetsiri ${ }^{35}$ found a significant association between use of high heels and repetitive strain injury in teachers $(\mathrm{OR}=1.60)$. Keegan $e t a l^{37}$ profiled footwear worn at time of fall by participants who fractured and those who did not and found that medium-to-high heel height was associated with increased risk of fracture of the foot $(\mathrm{OR}=2.0)$, distal forearm $(\mathrm{OR}=1.7)$, proximal humerus $(\mathrm{OR}=1.5)$, pelvis $(\mathrm{OR}=1.5)$ and shaft of the tibia/fibula $(\mathrm{OR}=1.7)$. Tencer et $a t^{40}$ found a significant association between high heels and fall risk in older adults $(\mathrm{OR}=1.9)$. Gabell et $a \hat{l}^{36}$ found that heel height habit was among the top 2 predisposing factors for falls in older adults even though no participant was wearing high heels at the time of falling. Moreover, past wear of high heels was associated with increased risk of multiple rather than single falls. Nagata $^{39}$ found that $74 \%$ of occupational stair injuries to women under the age of 24 involved high-heeled or semi-high-heeled shoes, with women wearing these 
shoes being particularly prone to fall after catching the heel on the edge of the steps. Sherrington and Menz, ${ }^{41}$ however, found that only $2 \%$ of participants were wearing high heels at time of fall-related hip fracture and that no association was found between tripping or slipping and use of high heels.

Two studies ${ }^{18} 38$ took a very different approach to assessing the association between use of high heels and injury. Rather than surveying people and comparing outcomes between those that were and were not wearing high heels, they used pre-existing data from major databases regarding ED presentation to profile the number of injuries presenting to ED that were clinically attributed by the ED physician to be caused by use of high heels. Williams and Haines ${ }^{18}$ studied ED presentations over a 5-year period in the Australian state of Victoria and found 240 ED presentations resulting from first-party injury from high heels. Women accounted for $98 \%$ of patients and men $2 \%$. The most common injury site was the ankle $(51 \%)$ followed by the foot including the toes $(26 \%)$. The most common age brackets were 20-24 (26\%) and 25-29 (19\%). Twelve presentations (5\%) concerned children up to and including the age of 14 with 24 further presentations (10\%) in the 15-19 age range. The estimated cost of the first-party injury presentations to the Victorian public hospital system was estimated to be $\$$ A71,579.62 over a 5-year period. In a larger-scale study, Moore $e t a l^{88}$ studied ED presentations over a 10 -year period in the US Consumer Product Safety Commission's National Electronic Injury Surveillance System, which provides a scalable estimate for the whole US. They identified 3294 ED presentations relating to first-party injury from high heels in women, which provides a US-wide estimate of 123355 presentations taking into account the sampling weight. The most common injury site was the ankle (39\%) followed by the foot (33\%). The most common injury type was strain or sprain $(53 \%)$ followed by fractures $(19 \%)$. The most common age brackets were 20-29 (33\%) and 30-39 (20\%). There were 4737 injuries (4\%) to children aged 0-9 and a further 17530 injuries (14\%) in the 10-19 age bracket.

Only one study ${ }^{18}$ presented any data regarding the association between high heels and second-party injury. In this study, which was assessed as high quality, the authors presented the number of second-party injuries from high heels over a 5-year period in Victoria in their ED presentations database and then excluded secondparty injuries from further analysis. There were $49 \mathrm{ED}$ presentations resulting from being stepped on by high heels and 16 resulting from assault with high heels.

\section{DISCUSSION}

This is the first review of the potential health impact of high heels from an epidemiological perspective. The first major finding is that the identified body of literature taking this approach (18 studies) is smaller than the body of literature taking a biomechanical approach, which a preliminary search ahead of this review estimated to be in the order of 100 studies. The second major finding is that there is strong evidence that high heels are associated with first-party injury but that scientific evidence regarding second-party injury is limited. The third major finding is the injury toll among underage girls including 4737 injuries to those under the age of 10 in the study by Moore et al. ${ }^{38}$ The fourth major finding is that the balance of evidence is in favour of an association between high heels and increased risk of both HV and musculoskeletal pain. The fifth major finding is that no evidence was found of an association between high heels and OA.

The biomechanical and epidemiological approaches both have their associated strengths and limitations and should be considered complementary. Combining evidence from both approaches, which is called triangulation, can strengthen and corroborate the evidence base. $^{42}$ In comparison with biomechanical studies of high heels, epidemiological studies do not rely on biomechanical proxies of clinical conditions, consider habitual exposure to high heels beyond the data collection session and tend to be conducted on larger samples. However, they tend to be observational, may be subject to recall bias regarding past exposure, may be affected by residual confounding and may not be able to separate the effects of different shoe parameters. With regard to confounding, for example, studies included in the current review have a wide variety of age ranges and the effects of high heels and the ageing process on outcomes may not be entirely separable. On the other hand, biomechanical studies such as that by Kerrigan et $a t^{43}$ can separate the effects of heel height and heel width. Recall bias may be particularly problematic in case-control studies, ${ }^{44}$ which may partly explain the negative findings of McWilliams et $a \hat{l}^{30}$ and Dawson et $a l^{29}$ regarding OA. The use of pre-existing databases as in the studies of Williams and Haines ${ }^{18}$ and Moore $e t a l^{38}$ offers a unique population-level insight into the burden of high heels-related injury and overcomes issues of selection bias in recruitment. However, as acknowledged by the authors, this approach may be subject to clinical misclassification bias-in the case of high heelsrelated injury, it is likely that the bias is in the direction of under-reporting of the role of high heels where alcohol was also a factor in ED admission. Moreover, although the epidemiological approach offers greater direct insight into clinical features than the biomechanical approach, differences in diagnostic criteria, grading systems and classifications may present a further limitation.

The balance of the evidence regarding the association between high heels and musculoskeletal pain, taking into account study quality, supports the existence of an association. This is corroborated by women's everyday experience of high heels as explored, for example, in the qualitative research of Dilley et al. ${ }^{8}$ All but one low quality study identified an association between high 
heels and $\mathrm{HV}$, which is corroborated by biomechanical evidence, for example, an increase in forefoot pressure and loading at the first metatarsal head. ${ }^{45-48}$ The lack of association between high heels and OA is an unexpected finding, which may partly be explained by low study quality, recall bias regarding past shoe exposure and a particularly small sample size $(n=29$ for cases $)$ in one study. ${ }^{29}$ In contrast, there is considerable biomechanical evidence suggesting an association between high heels and $\mathrm{OA}$ of the knee, for example, increased knee flexion ${ }^{49-52}$ and patellofemoral joint pressure. ${ }^{53}$

The body of evidence regarding first-party injury is larger than the other outcomes in this review and is consistently positive with the exception of one study ${ }^{41}$ in which only footwear worn at the time of fall was considered and very few participants (2\%) in this study were wearing high heels at the time of their fall, which would result in statistical power problems in comparing the outcome of times when high heels were or were not worn. Nagata ${ }^{39}$ usefully highlights the potential hazard of climbing stairs in high heels, while Gabell et $a l^{36}$ highlight that the physiological impact of wearing high heels may predispose women to a greater risk of falling even when they are not wearing high heels at the time of their fall. This finding should be interpreted in combination with evidence of stiffening and shortening of the Achilles tendon ${ }^{54}$ and radiographic evidence of alterations to the spinopelvic structure ${ }^{55}$ associated with use of high heels. Indeed, these structural adaptations may be a possible explanation for the finding of Gabell et $a l^{36}$ that high heels wearing habit may predispose women to falling even when not wearing high heels at the time of the fall. The two studies assessing ED presentations ${ }^{18} 38$ provide insight into the clinical significance of first-party injury from high heels and especially the larger study by Moore et $a l^{88}$ gives insight into both the clinical and demographic spectrum of injuries incurred. The injury toll among girls under the legal age of adulthood including a large number of under $10 \mathrm{~s}$ is striking. However, neither study classified age in a way that allows precise division of legal adults from those below the legal age of adulthood.

In this context, it is important to note that there are styles of high heels specifically marketed for children, ${ }^{5657}$ there is no age restriction on the sale of high heels in countries such as England and Australia, where such restrictions exist for many other items, ${ }^{20} 21 \quad 5859$ and in our experience few high schools prohibit girls under the legal age of adulthood from wearing high heels to school functions such as proms, while some schools encourage it (M. Barnish, personal communication). It is also important to note that some employers' dress codes and social event organisers require women to wear high heels. ${ }^{9-12}$ Some health-related organisations have called for compulsory wear of high heels at work to be outlawed, however to the best of our knowledge no country has enacted such legislation. For example, in 2009 the Society of Chiropodists and Podiatrists (UK) made a statement that "women workers should not be made to adhere to a dress code that can damage their feet and should have the choice to wear footwear that will not leave them prone to long term foot health problems." ${ }^{\prime 10}$ In light of the findings of our review with regard to $\mathrm{HV}$, pain and especially injury, we recommend that health-related organisations engage in further constructive dialogue with governments and other policymakers regarding the compulsion to wear high heels at work as well as social events and regarding access to high heels among girls under the legal age of adulthood.

We have a number of suggestions for future research. First, noting that the absence of evidence is not evidence of the absence of a relationship, ${ }^{60}$ further epidemiological research is required to assess the potential association between high heels and $\mathrm{OA}$ as suggested by biomechanical studies but not evidenced in the current review. Second, the risk of second-party injury associated with clothing in general and high heels in particular is an area that has been under-researched and deserves further attention. Third, building on the work of Dilley et $a l^{8}$ and Woodward, ${ }^{7}$ it is recommended to investigate the level of awareness of health issues relating to high heels, what role this plays in footwear choice and whether certain categories of women (eg,competitive sportswomen and health professionals) are less likely to wear high heels than the general population. These studies would help determine the likelihood of a health educational intervention being effective, noting that considerable information on high heels and health is already available to the public from sources such as WebMD $^{61}$ and media reports of research on high heels. Fourth, we suggest that use of high heels is taken into account in future studies of women's and musculoskeletal health to address the potential confounding effects of the use of high heels on the relationships being investigated.

This review has several notable strengths. First, it provides what is to our knowledge the first review of the relationship between high heels and health from an epidemiological perspective. Second, it situates the evidence in the context of wider public debate. Third, it offers a systematic approach to inclusion, data extraction, quality assessment and reporting in order to minimise the risk of bias. Fourth, drawing on the linguistic skills of the authors, articles in seven languages could be considered for inclusion. Fifth, this review included a range of clinically relevant outcomes in order to maximise clinical and policy relevance.

There are, however, a few limitations to this review that should be taken into account. First, while the range of eligible languages was relatively wide, it was focused on European languages and may not allow complete coverage of the world's literature. Second, two articles (4\% of those selected for full-text screening) could not be retrieved. Third, while two reviewers conducted screening, data extraction and quality assessment, only 
one reviewer designed and conducted the searches. Fourth, the variety of outcome measures and the cut-offs for what constituted high heels precluded the use of meta-analysis. If these aspects could be betterstandardised in future epidemiological research on high heels, a meta-analysis could be considered when this systematic review is due for update. In addition, the variability of cut-offs for heel height and the frequent failure of studies to take into account factors such as heel shape may reduce the precision of the findings and in some cases may explain the absence of significant results. With regard to heel shape, it is possible that the effect of stiletto, platform and wedge heels for example, may differ and that curved heels and 'heelless heels', which are now fashionable, may have a different effect than more traditional heel styles.

Here we present a systematic review of epidemiological evidence relating the use of high heels to musculoskeletal health outcomes. A future review on this topic could seek to integrate the hitherto relatively separate bodies of biomechanical and epidemiological literature.

Contributors MSB was responsible for conceptualisation and project management, search design and execution. MSB and JB were responsible for screening, data extraction, quality assessment and interpretation. MSB prepared the first draft. MSB and JB were responsible for revisions and approval to submit manuscript. MSB is the guarantor.

Funding This research received no specific grant from any funding agency in the public, commercial or not-for-profit sectors.

Competing interests None declared.

Provenance and peer review Not commissioned; externally peer reviewed.

Data sharing statement No additional data are available.

Open Access This is an Open Access article distributed in accordance with the Creative Commons Attribution Non Commercial (CC BY-NC 4.0) license, which permits others to distribute, remix, adapt, build upon this work noncommercially, and license their derivative works on different terms, provided the original work is properly cited and the use is non-commercial. See: http:// creativecommons.org/licenses/by-nc/4.0/

\section{REFERENCES}

1. Small L. Killer heels: the art of the high-heeled shoe. Munich: Prestel, 2014.

2. Guéguen N. High heels increase women's attractiveness. Arch Sex Behav 2015;44:2227-35.

3. Morris PH, White J, Morrison ER, et al. High heels as supernormal stimuli: how wearing high heels affects judgements of female attractiveness. Evol Hum Behav 2013;34:176-18.

4. Cialdini RB, Goldstein NJ. Social influence: compliance and conformity. Annu Rev Psychol 2004;55:591-621.

5. Douglas M, Ney S. Missing persons: a critique of the social sciences. Berkeley, CA: University of California Press, 1998.

6. Craik J. Fashion: the key concepts. Oxford: Berg, 2009.

7. Woodward S. Why women wear what they wear. New York: Berg, 2007.

8. Dilley R, Hockey J, Robinson V, et al. Occasions and non-occasions: identity, femininity and high-heeled shoes. Eur $J$ Women's Stud 2015;22:143-58.

9. Linder M. Smart women, stupid shoes, and cynical employers: the unlawfulness and adverse health consequences of sexually discriminatory workplace footwear requirements for female employees. J Corp Law 1997;22:295-329.

10. College of Podiatry. TUC congress 2009 motion-high heels. 2009. http://www.scpod.org/news/press-release-archive/ news-coverage-tuc-motion-on-high-heels/ (accessed 9 Dec 2015).
11. Freeman H. Can't do heels? Don't do Cannes. The Guardian, 20 May 2015.

12. Bunbury S. Cannes Film Festival's 'high-heels only' red carpet policy draws ire from stars. Sydney Morning Herald, 20 May 2015.

13. Goldthwait JE. Essentials of body mechanics in health and disease. London: JB Lippincott, 1952.

14. Rossi WA. Footwear: the primary cause of foot disorders. Podiatry Management, February 2001.

15. Cronin NJ. The effects of high heeled shoes on female gait: a review. J Electromyogr Kinesiol 2014;24:258-63.

16. Nix S, Smith M, Vincenzo B. Prevalence of hallux valgus in the general population: a systematic review and meta-analysis. J Foot Ankle Res 2010;3:21.

17. Katz BP, Freund DA, Heck DA, et al. Demographic variation in the rate of knee replacement: a multi-year analysis. Health Serv Res 1996;31:125-40.

18. Williams CM, Haines TP. An exploration of emergency department presentations related to high heel footwear in Victoria, Australia, 2006-2010. J Foot Ankle Res 2014;7:4.

19. Giancoli DG. Physics: principles with applications. Upper Saddle River, NJ: Pearson Education, 2004.

20. Buying and carrying knives: the law. https://www.gov.uk/ buying-carrying-knives (accessed 9 Dec 2015).

21. Weapons licensing - the Law. https://www.police.qld.gov.au/ programs/weaponsLicensing/fees/faqs/lawFaqs.htm (accessed 19 Aug 2015).

22. Moher D, Liberati A, Tetzlaff J, et al. Preferred reporting items for systematic reviews and meta-analyses: the PRISMA statement. Ann Intern Med 2009;151:264-9.

23. Inches to $\mathrm{cm}$ (centimeters) converter. http://www.inches-to-cm.com/ (accessed 9 Dec 2015).

24. Daley DJ, Myint PK, Gray RJ, et al. Systematic review on factors associated with medication non-adherence in Parkinson's disease. Park Relat Disord 2012;18:1053-61.

25. Dufour AB, Casey VA, Golightly YM, et al. Characteristics associated with hallux valgus in a population-based foot study of older adults. Arthritis Care Res 2014;66:1880-6.

26. Menz HB, Morris ME. Footwear characteristics and foot problems in older people. Gerontol 2005;51:346-51.

27. Nguyen U-SDT, Hillstrom HJ, Li W, et al. Factors associated with hallux valgus in a population-based study of older women and men: the MOBILIZE Boston Study. Osteoarthritis Cartilage 2010;18:41-6.

28. Dawson J, Thorogood M, Marks S-A, et al. The prevalence of foot problems in older women: a cause for concern. $J$ Public Health Med 2002;24:77-84.

29. Dawson J, Juszczak E, Thorogood M, et al. An investigation of risk factors for symptomatic osteoarthritis of the knee in women using a life course approach. J Epidemiol Community Health 2003;57:823-30.

30. McWilliams DF, Muthuri S, Muir KR, et al. Self-reported adult footwear and the risks of lower limb osteoarthritis: the GOAL case control study. BMC Musculoskelet Disord 2014;15:308.

31. Chua YP, Tan WJ, Yahya TSTA, et al. Prevalence of nontraumatic foot pain among urban young working women and its contributing factors. Singapore Med J 2013;54:630-3.

32. Hong $\mathrm{W}-\mathrm{H}$, Lee $\mathrm{Y}-\mathrm{H}$, Chen $\mathrm{H}-\mathrm{C}$, et al. Influence of heel height and shoe insert on comfort perception and biomechanical performance of young female adults during walking. Foot Ankle Int 2005;26:1042-8.

33. Yung-Hui L, Wei-Hsien H. Effects of shoe inserts and heel height on foot pressure, impact force, and perceived comfort during walking. Appl Ergon 2005;36:355-62.

34. de Castro AP, Rebelatto JR, Aurichio TR. The relationship between foot pain, anthropometric variables and footwear among older people. Appl Ergon 2010;41:93-7.

35. Chaiklieng S, Suggaravetsiri P. Risk factors for repetitive strain injuries among school teachers in Thailand. Work 2012;41:2510-15.

36. Gabell A, Simons MA, Nayak USL. Falls in the healthy elderly: predisposing causes. Ergonomics 1985;28:965-75.

37. Keegan THM, Kelsey JL, King AC, et al. Characteristics of fallers who fracture at the foot, distal forearm, proximal humerus, pelvis, and shaft of the tibia/fibula compared with fallers who do not fracture. Am J Epidemiol 2004;159:192-203.

38. Moore JX, Lambert B, Jenkins GP, et al. Epidemiology of high-heel shoe injuries in U.S. women: 2002 to 2012. J Foot Ankle Surg 2015;54:615-19.

39. Nagata $\mathrm{H}$. Occupational accidents while walking on stairways. Saf Sci 1991;14:199-211.

40. Tencer AF, Koepsell TD, Wolf ME, et al. Biomechanical properties of shoes and risk of falls in older adults. J Am Geriatr Soc 2004;52:1840-6.

41. Sherrington $\mathrm{C}, \mathrm{Menz} \mathrm{HB}$. An evaluation of footwear worn at the time of fall-related hip fracture. Age Ageing 2003;32:310-14. 
42. Denzin N. Sociological methods: a sourcebook. Piscataway, NJ: Aldine Transaction, 2006.

43. Kerrigan DC, Lelas JL, Karvosky ME. Women's shoes and knee osteoarthritis. Lancet 2001;357:1097-8.

44. Chouinard E, Walter S. Recall bias in case-control studies: an empirical analysis and theoretical framework. J Clin Epidemiol 1995;48:245-54.

45. Cong Y, Cheung JT, Leung AK, et al. Effect of heel height on in-shoe localized triaxial stresses. J Biomech 2011;44:2267-72.

46. Mandato MG, Nester $\mathrm{E}$. The effects of increasing heel height on forefoot peak pressure. J Am Podiatr Med Assoc 1999;89:75-80.

47. Nyska M, McCabe $\mathrm{C}$, Linge $\mathrm{K}$, et al. Plantar foot pressures during treadmill walking with high-heel and low-heel shoes. Foot Ankle Int 1996;17:662-6.

48. Snow RE, Williams KR, Holmes GB Jr. The effects of wearing high heeled shoes on pedal pressure in women. Foot Ankle 1992;13:85-92.

49. Kerrigan DC, Todd MK, Riley PO. Knee osteoarthritis and high-heeled shoes. Lancet 1998;351:1399-401.

50. Mika A, Oleksy L, Mika P, et al. The influence of heel height on lower extremity kinematics and leg muscle activity during gait in young and middle-aged women. Gait Posture 2012;35: 677-80.

51. Blanchette MG, Brault JR, Powers CM. The influence of heel height on utilized coefficient of friction during walking. Gait Posture 2011;34:107-10.
52. Ebbeling CJ, Hamill J, Crussemeyer JA. Lower extremity mechanics and energy cost of walking in high-heeled shoes. J Orthop Sports Phys Ther 1994;19:190-6.

53. Ho KY, Blanchette MG, Powers CM. The influence of heel height on patellofemoral joint kinetics during walking. Gait Posture 2012;36:271-5

54. Csapo R, Maganaris CN, Seynnes OR, et al. On muscle, tendon and high heels. J Exp Biol 2010;213:2582-8.

55. Dai M, Li X, Zhou X, et al. High-heeled-related alterations in the static sagittal profile of the spino-pelvic structure in young women. Eur Spine J 2015;24:1274-81.

56. Kids high heels. http://www.ebay.com/bhp/kids-high-heels (accessed 9 Dec 2015).

57. High heels for kids on Amazon.com. http://www.amazon.com/gp/ feature.html?ie=UTF8\&docld=1001331111 (accessed Dec 2015)

58. Liquor Control Reform Act 1998-Sect 119. http://www.austlii.edu. au/au/legis/vic/consol_act/lcra1998266/s119.html (accessed 9 Dec 2015).

59. Alcohol licensing. https://www.gov.uk/guidance/alcohol-licensing (accessed 9 Dec 2015)

60. Altman DG, Bland JM. Statistics notes: absence of evidence is not evidence of absence. BMJ 1995;311:485.

61. Slideshow: The Worst Shoes for Your Feet. http://www.webmd.com/ pain-management/ss/slideshow-worst-shoes-for-your-feet (accessed 9 Dec 2015). 